\title{
Bainite Formation in High Carbon Copper Bearing Steels
}

\author{
G. Fourlaris and A.J. Baker
}

School of Materials, The University of Leeds, Leeds LS2 9JT, U.K.

\begin{abstract}
The bainite reaction has been studied extensively in steels and other non-ferrous alloys. However up to present a significant disagreement exists regarding the nature and the mechanism of this phase transformation. During the isothermal bainitic transformation in hypereutectoid carbon steels alloyed with copper or copper and nickel, it was found that at all the transformation temperatures studied, the formation of equally copper supersaturated bainitic ferrite and cementite always occurred. This observation implies the formation of bainitic ferrite and cementite from the parent austenite phase without redistribution of the alloying elements, since the solubility of copper in cementite is negligible and very low in bainitic ferrite. By carefully designing suitable tempering treatments, it is possible to produce copper precipitation within tempered bainitic ferrite in both types of steels using low tempering temperatures. In addition, copper precipitation within the tempered bainitic cementite of the copper steel has been found to occur within a narrow tempering temperature region. However, the orientation relationship of the copper precipitation, within the tempered bainitic cementite and within the tempered bainitic ferrite has been found to be different. The interpretation of these experimental data strongly supports the theory promoting formation of the bainite through a shear controlled type of mechanism.
\end{abstract}

\section{INTRODUCTION}

The bainite reaction has been studied extensively in steels and other non-ferrous alloys [1-6]. However up to present a significant disagreement exists regarding the nature and the mechanism of this phase transformation [7-13]. Three distinct theories have been developed, attempting to explain the bainite reaction.

The first theory [3] considers the bainite transformation to be an extension of the martensite transformation to higher temperatures. In steels using this model, austenite transforms to supersaturated bainitic ferrite by a shear mechanism followed by carbide precipitation within the ferrite [14]. The rate of reaction, or the extent of shear, is controlled by the diffusion of carbon away from the austenite/ferrite interface, either into the austenite which becomes enriched in carbon, or into the carbides $[6,14]$.

The second theory postulates that the same mechanism as that governing both the pearlite reaction and the formation of Widmanstatten ferrite, applies to lower temperature transformation reactions such as the bainite reaction. Under this generalised microstructural definition of bainite, bainite is the product of the diffusional nucleation and the competitive diffusional growth of the two phases comprising the products of a eutectoid reaction [7]. In steels a local equilibrium is established at the austenite/ferrite interface [15] and the carbides precipitate at the interface [16]. One of the models derived from this theory is the ledge mechanism [17].

The third theory views bainite as having its own $\mathrm{C}$-curve on a time-temperature-transformation (TTT) diagram, whose upper limiting temperature, termed the "Kinetic $\mathrm{B}_{\mathrm{S}}$ " is significantly lower from the eutectoid temperature of the steel [4]. Between "Kinetic $\mathrm{B}_{\mathrm{s}}$ " and "Kinetic $\mathrm{B}_{\mathrm{f}}$ " (defining the temperature range in which bainite formation terminates before total transformation occurs), bainite forms from the transformed austenite in amounts ranging from $100 \%$ at $\mathrm{B}_{\mathrm{S}}$ to $0 \%$ at $\mathrm{B}_{\mathrm{f}}$. This theory involves the concept of "transformation stasis" during which bainite transformation ceases for periods ranging from a few seconds to months before the bainite reaction resumes again, leading to complete transformation of austenite, presumably by a mode similar to the pearlite reaction.

Unfortunately, none of the models derived from these theories are capable of explaining all aspects of bainite transformation and currently, the bainite reaction is regarded, as a complex shear type transformation in which diffusion plays a significant role [6-7,13].

The addition of copper to a hypereutectoid steel and to a hypereutectoid nickel steel has been made in order to study the precipitation reactions that would occur during isothermal bainite transformation and 
to provide information regarding the nature and mechanism of the bainite reaction in high carbon steels. Parallel studies of the isothermal pearlite reaction in the same type of steels revealed the presence of interphase $\varepsilon$-Cu precipitates within both the pearlitic ferrite and cementite of copper steels [18-20]. If the bainite reaction is a diffusion controlled reaction [21] then similar precipitation sequences could be expected to occur during the isothermal bainitic transformation in hypereutectoid copper and coppernickel steels. In copper alloyed steels formation of cementite occurs without the incorporation of copper in the chemistry of the carbide in medium and low alloy carbon steels.

\section{EXPERIMENTAL PROCEDURE}

The composition of the experimental steels is given in Table 1 .

Table 1: Composition of steels in w.t. \% .

\begin{tabular}{cccccccc}
\hline Fe & C & Si & P & S & Ni & Cu & Mn \\
\hline 96.3 & 0.97 & 0.0678 & 0.0020 & 0.0112 & 0.0249 & 2.73 & 0.0704 \\
86.14 & 0.94 & 0.0632 & 0.0031 & 0.0134 & 5.35 & 7.13 & 0.0761 \\
\hline
\end{tabular}

Heat treatment, on samples of a $3 \mathrm{~mm}$ on edge cube, initially included an austenitisation step performed at $1050^{\circ} \mathrm{C}$ for 30 minutes in a tube furnace under an argon atmosphere. After austenitisation samples were quickly transferred to a lead-tin bath. Isothermal heat treatments in the bath were performed within the temperature range $200^{\circ} \mathrm{C}$ to $400^{\circ} \mathrm{C}$. Extensive details regarding specimen preparation techniques for SEM and TEM microscopy are provided on a different publication [23].

A Philips EM 430 High Voltage Electron Microscope was used for the TEM Examination.

\section{RESULTS}

The study of the isothermal bainitic transformation was carried out on hypereutectoid copper and copper -nickel steels, since in these alloys the progress of the transformation is relatively slow and it is possible to follow the different stages of this reaction more readily.

\subsection{Bainite reaction in copper steels}

SEM characterisation of the material that had been austenitised and isothermally transformed within the bainite region $\left(400^{\circ} \mathrm{C}-250^{\circ} \mathrm{C}\right)$ revealed the presence of typical bainitic colonies nucleating at prior austenite grain boundaries and expanding to consume the prior austenite grain. Examples of the bainitic microstructures obtained on this steel at $350^{\circ} \mathrm{C}$ are presented in Figure 1 . In Figure 1a the microstructure consists of a mixture of bainite and martensite formed during the ice brine quenching of the untransformed austenite, whereas in Figure $1 \mathrm{~b}$ the fully bainitic structures obtained after the end of the reaction at this temperature can be seen. No partition of copper between the martensite and bainite phases was found, during the initial stages of transformation, using the EDS attachment of the SEM. In addition it was found that no residual untransformed austenite exists.

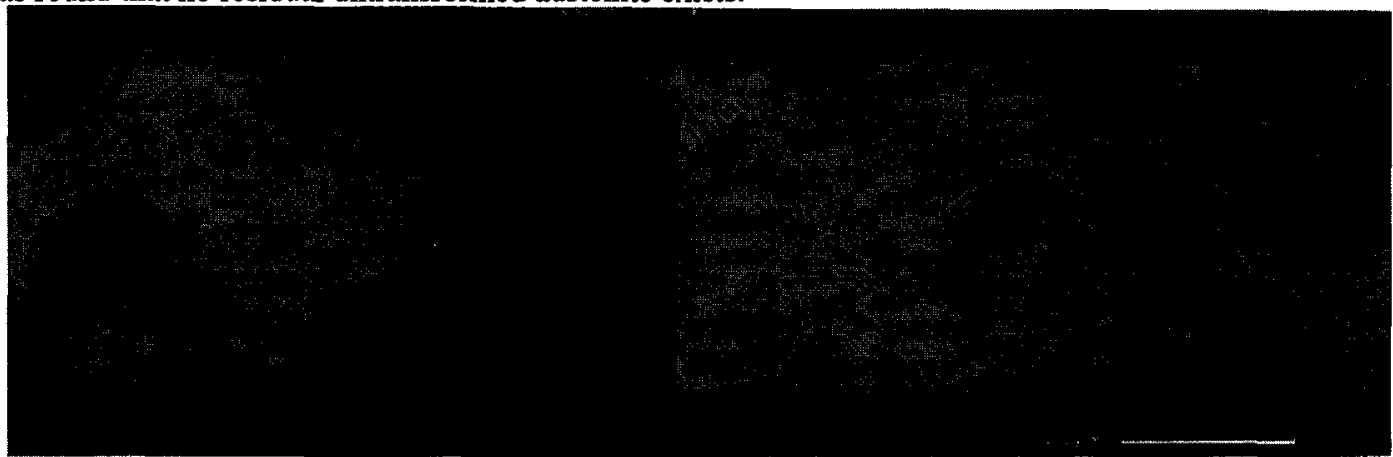

Figure 1: SEM micrographs of upper bainite produced in $\mathrm{Fe}-0.95 \mathrm{C}-3 \mathrm{Cu}$ by isothermal transformation at $350^{\circ} \mathrm{C}$ for 20 minutes (Fig.1a) or 30 minutes (Fig.1b). 
Examination by TEM revealed the fine details of the microstructure, as can be seen in Figure 2. The microstructure is that of upper bainite with a relatively high dislocation density within the bainitic ferrite. The bainitic cementite (its presence verified by selected area electron diffraction) is located at the bainitic ferrite interlath boundaries. Extensive selected area diffraction examination failed to identify any other phase present apart from bainite. EDX microanalysis (STEM mode), revealed the presence of equal amounts of copper supersaturation in both the bainitic ferrite and bainitic cementite. The existence of this copper supersaturation within the bainitic cementite was unexpected. Prolonging the holding time at the $350^{\circ} \mathrm{C}$ isothermal temperature for as long as several days did not alter the characteristics of the transformed bainitic microstructure. The bainitic ferrite and bainitic cementite both remained supersaturated in copper. The conctusion has been reached that at the temperatures at which the isothermal bainitic transformation was produced, there was probably a barrier to the nucleation and growth of copper from the supersaturated phases.
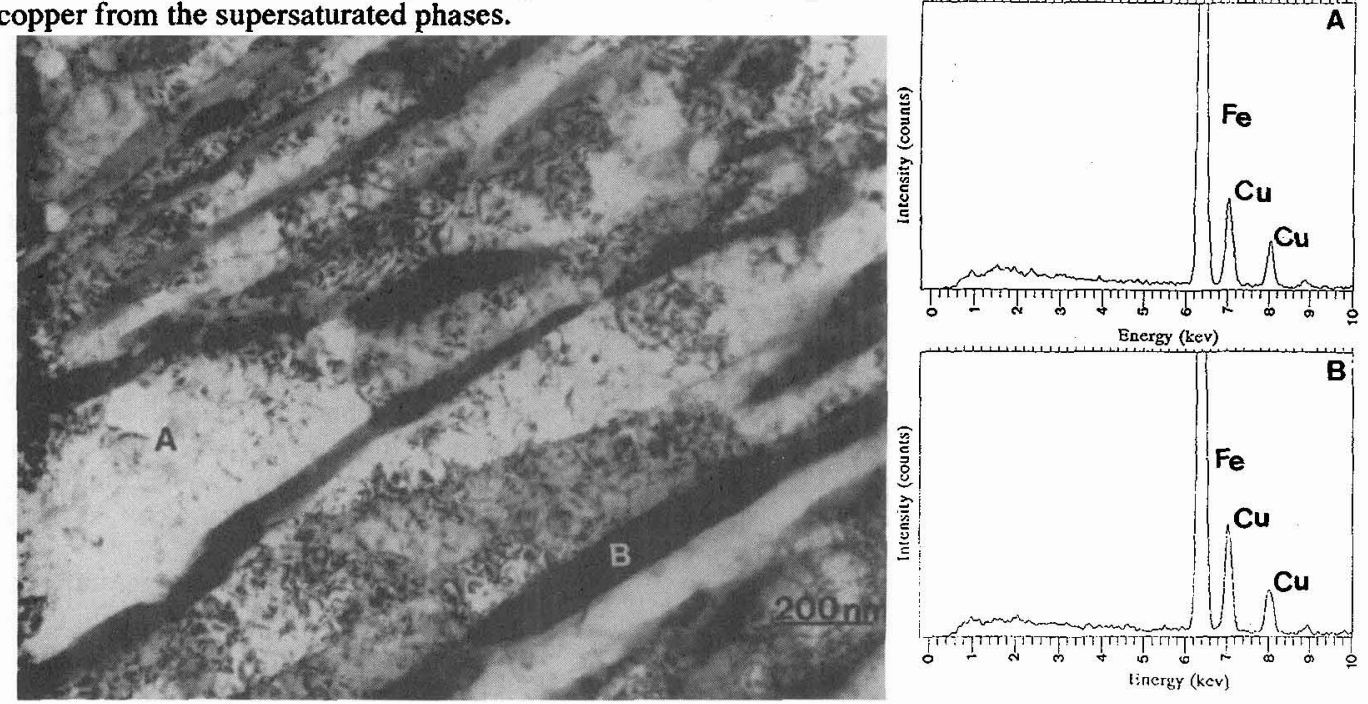

Figure 2 : Bright field TEM micrograph of upper bainite produced by isothermal transformation at $350^{\circ} \mathrm{C}$ for 2 hours. Note the absence of $\varepsilon-\mathrm{Cu}$ precipitation and the presence of equal copper supersaturation within bainitic cementite and bainitic ferrite

In order to relieve the supersaturation in copper, at least within bainitic ferrite, a variety of tempering experiments were carried out. Initially, a sample was isothermally transformed at $350^{\circ} \mathrm{C}$ for $36 \mathrm{~h}$ and then tempered at $500^{\circ} \mathrm{C}$ for $7.5 \mathrm{~h}$. It was confirmed that this heat treatment resulted in the precipitation of $\varepsilon-\mathrm{Cu}$ from the supersaturated bainitic ferrite. EDX microanalysis (STEM mode) confirmed that bainitic cementite still remained highly supersaturated in copper following this tempering experiment. It was concluded that a nucleation barrier existed for the copper supersaturated bainitic cementite and this situation created the need for the design of a suitable precipitation treatment that would confirm this supersaturation in copper within cementite, without in the process altering significantly the bainitic microstructure. Therefore, a sample was isothermally transformed at $350^{\circ} \mathrm{C}$ for 65 minutes and then tempered at $550^{\circ} \mathrm{C}$ for 24 hours. This tempering experiment resulted in $\varepsilon$-Cu precipitates visible within both tempered bainitic ferrite and bainitic cementite. In Figure 3 , where a pair of dark and bright field TEM micrographs is provided, it can be seen especially in the dark field image,that carbides possess within them a very fine dispersion of spheroidal particles and these particles are $\varepsilon$-Cu that have precipitated within the carbide during the tempering treatment. The precipitates have a uniform fine size (approximately 3-6 $\mathrm{nm}$ ) and a spheroidal shape. They form a small colony inside the carbide covering the area which the initial bainitic cementite occupied, before later growth of the carbide occurred during spheroidisation. For the production of the dark field image the $\{111\} \varepsilon-\mathrm{Cu}$ was used from the $\varepsilon-\mathrm{Cu}$ precipitates within the cementite. It can be seen that the majority of the $\varepsilon$-Cu precipitates within cementite have a different orientation relationship from that of the $\varepsilon-\mathrm{Cu}$ precipitates in the adjacent ferrite. The fact that at this tempering treatment $\varepsilon$-Cu precipitation also occurs on a very fine scale within the bainitic cementite is very important. 


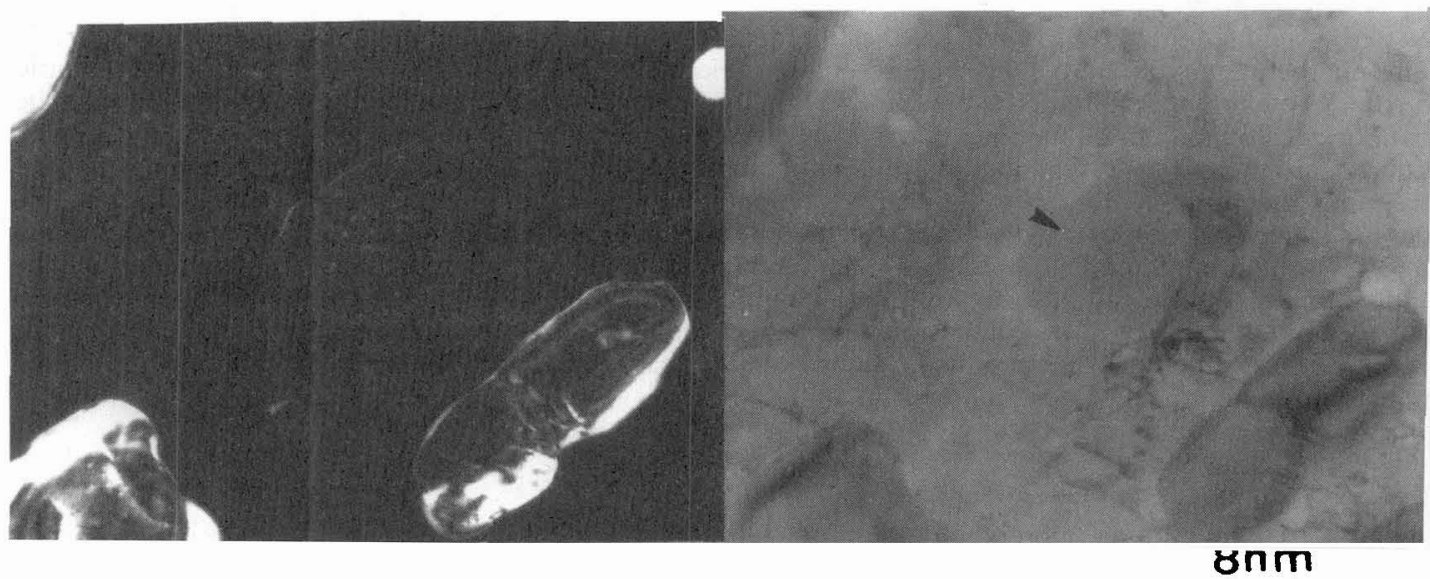

Figure 3: A pair of dark and bright field TEM micrographs of $\varepsilon$-Cu precipitation within tempered bainitic ferrite, produced by isothermal transformation at $350^{\circ} \mathrm{C}$ for 65 minutes followed by tempering at $550^{\circ} \mathrm{C}$ for 24 hours.

These precipitation effects that occurred during the tempering treatment of the initially produced supersaturated bainitic cementite, showed that despite the unfavourable conditions, once the nucleation barrier is overcome supersaturated copper within the carbide comes out of solution and produces $\varepsilon-\mathrm{Cu}$ precipitation within bainitic cementite. $\varepsilon$-Cu precipitates were also formed within the bainitic ferrite at even lower tempering temperatures because the nucleation problem is more easily overcome within ferrite than within cementite. $\varepsilon$ - $\mathrm{Cu}$ particles not only form during tempering but also coarsen due to the prolonged holding of the sample at the tempering temperature, and this results in a variety of sizes and shapes of randomly distributed $\varepsilon$-Cu particles within ferrite.

Essentially the same results were obtained with specimens treated at different temperatures of isothermal bainitic transformation.

\subsection{The bainite reaction in copper-nickel steels}

Isothermal bainitic transformation has been carried out in samples of this steel within the temperature range $350^{\circ} \mathrm{C}-250^{\circ} \mathrm{C}$. However, due to the high levels of copper and nickel alloy additions the reaction is very sluggish and in fact it takes several days before the transformation is completed. Examples of the resulting microstructures are shown in the SEM micrographs of Figure 4. It can be seen (Fig.4a) that a fully bainitic structure is obtained with a high density of non-lamellar bainitic cementite present in the microstructure. Similar microstructures were obtained for the samples isothermally transformed at $250^{\circ} \mathrm{C}$ for 21 days (Fig. 4b). Moreover, ferrite with a massive appearance is readily visible. The only difference observed is the refinement of the bainitic microstructure produced as the isothermal transformation temperature is lowered. No partition of either copper or nickel between bainitic cementite and bainitic ferrite was detected. In fact as the TEM examination revealed equal levels of copper and nickel supersaturation exist in both bainitic cementite and bainitic ferrite.

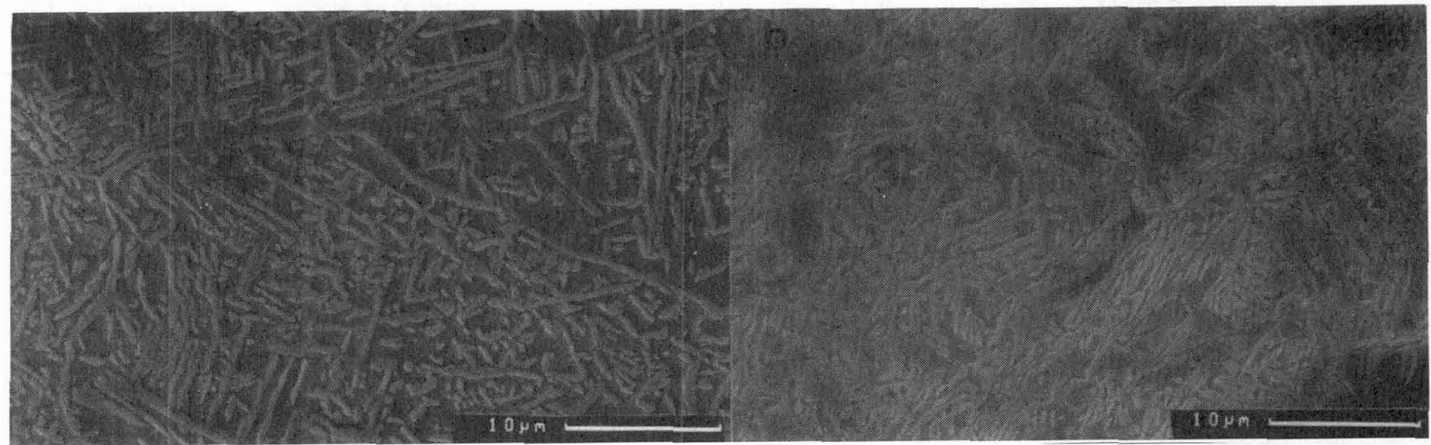

Figure 4 : SEM micrograph of bainite produced in Fe-0.95C-5Ni-7Cu by isothermal transformation at $350^{\circ} \mathrm{C}$ for 12 days (Fig.4a) or at $250^{\circ} \mathrm{C}$ for 21 days (Fig.4b). 


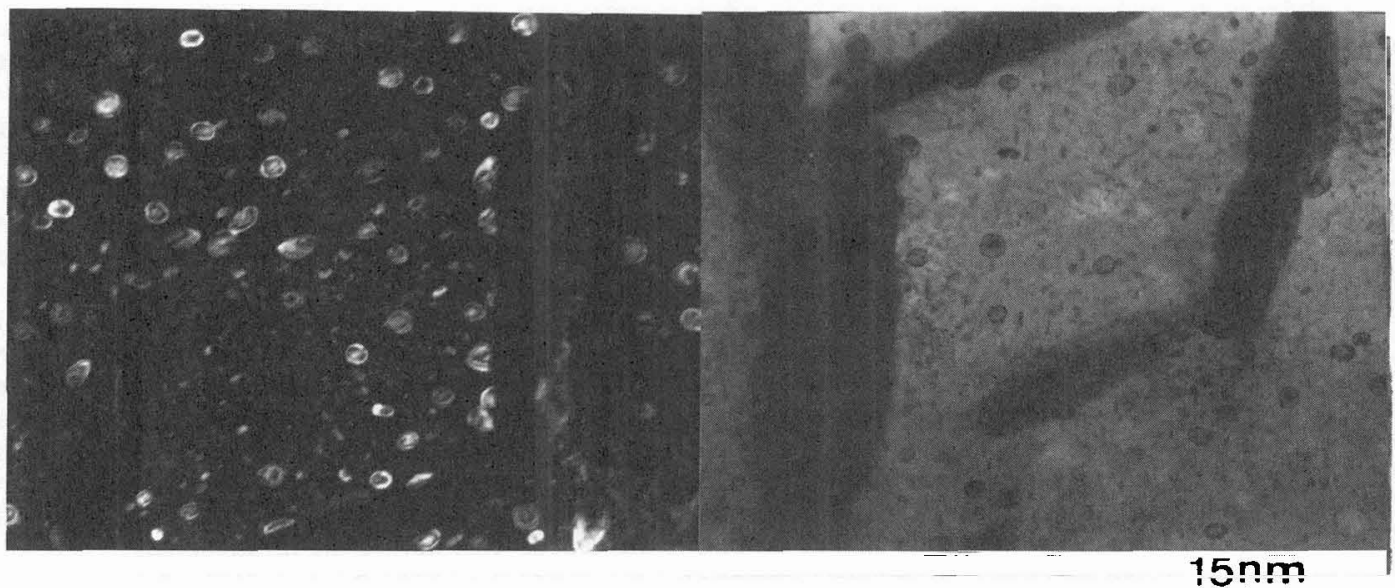

Figure 5: A pair of dark and bright field TEM micrographs of $\varepsilon-\mathrm{Cu}$ precipitation within tempered bainitic ferrite, produced by isothermal transformation at $250^{\circ} \mathrm{C}$ for 21 days followed by tempering at $550^{\circ} \mathrm{C}$ for 24 hours.

During isothermal bainitic transformation equally supersaturated bainitic cementite and bainitic ferrite were always produced at all temperatures of isothermal transformation employed, in full agreement with the results obtained previously in the case of the copper steel. An absence of copper precipitation was always observed and extensive SADP analysis confirmed that the only phases present were bainitic cementite and bainitic ferrite. As in the studies of the copper steel, tempering of the bainitic mictrostructures obtained in the copper-nickel steel was carried out. A sample was isothermally transformed at $250^{\circ} \mathrm{C}$ for 21 days, then tempered at $550^{\circ}$ for 24 hours. $550^{\circ} \mathrm{C}$ is the highest possible tempering temperature that can be used on this alloy, since due to the combined additions of copper and nickel the eutectoid point of this alloy is predicted to be at $\approx 560^{\circ} \mathrm{C} \mathrm{[23].} \mathrm{The} \mathrm{microstructure} \mathrm{at} \mathrm{the} \mathrm{level} \mathrm{of}$ the SEM examination appears similar to the microstructures presented in Figure $4 b$, apart from the fact that limited spheroidisation of the bainitic cementite has occurred.

However careful TEM examination revealed that a reduction in the level of the copper supersaturation of the bainitic ferrite has occurred leading to the production of modified in chemistry $\varepsilon-\mathrm{Cu}$ precipitates, as can be seen in the TEM micrographs of a tempered sample at $550^{\circ} \mathrm{C}$ for 24 hours (Fig. 5). Moreover, the tempered bainitic carbides appear very thick and prevent the clarification of whether this heat treatment has also produced copper precipitation within the tempered bainitic cementite. However, EDX microanalysis (STEM mode), confirmed the absence of any reduction of copper supersaturation within the tempered bainitic cementite.

Similar results were also obtained on other samples of this steel isothermally transformed at $200^{\circ} \mathrm{C}$ for 30 days, followed by tempering at $550^{\circ} \mathrm{C}$ for 24 hours. It was confirmed that a the general trend also exists in this alloy for the production of $\varepsilon-\mathrm{Cu}$ precipitates, at least within the tempered bainitic ferrite, which is in agreement with the results obtained from the copper steel.

\section{DISCUSSION}

As discussed earlier, bainitic microstructures that are produced initially exhibit an absence of copper precipitation in hypereutectoid copper and copper-nickel steels. However copper has been retained in a supersaturated state within both the bainitic ferrite and bainitic cementite constituents. By tempering the bainitic microstructures under carefully controlled conditions it is possible to produce $\varepsilon$-Cu precipitates within both bainite constituents of copper steel and $\varepsilon-\mathrm{Cu}$ precipitates at least within the tempered bainitic ferrite of copper-nickel steel.

Since the undercooling (from the solvus temperature) during isothermal bainitic transformation is large the thermodynamic driving force for the formation of bainite is very high. During the early stages of bainite formation the austenite/ferrite and austenite/cementite interfaces are migrating rapidly and the time available for the formation of $\varepsilon-\mathrm{Cu}$ precipitates on these migrating interfaces is limited. Moreover; 
since the formation of a nucleus must be accompanied by the successive growth of the nucleus to a critical size that will permit the formation of a stable precipitate, it is likely that, even if nuclei are formed at the austenite/cementite and austenite/ferrite interfaces they may remain at a subcritical size and redissolve after the passage of the interfaces. In either of these situations any bainitic ferrite and cementite that are formed will remain supersaturated in copper with approximately equal levels of supersaturation. An extensive analysis, why copper rich precipitates were only observed within tempered bainitic cemenite at a tempering temperature of $550^{\circ} \mathrm{C}$ was provided in a previous publication [23], where it was shown that at temperatures less than $550^{\circ} \mathrm{C}$, i.e. at $500^{\circ} \mathrm{C}$, even if copper precipitates were formed they should have had a radius of less than $0.2 \mathrm{~nm}$, which would have been impossible to observe .

The experimental evidence based on EDX and SADP analyses showed an absence of copper precipitation and similar levels of supersaturation within both bainitic constituents. This observation would be indicative of the growth of both the bainitic ferrite and bainitic cementite directly from austenite without a reconstructive mechanism. Such an observation requires that bainitic ferrite and cementite form from their parent austenite through a shear type mechanism. If a diffusion controlled mechanism had been operational, thermodynamic considerations would have required copper to have partitioned away from the growing cementite. Instead, equally copper-supersaturated bainitic ferrite and cementite form which implies that a diffusion controlled mechanism is not operational, at least during the initial stages.

The following theory has been formulated based on the current results on copper and copper nickel steels regarding the mechanism of bainitic formation: The initial formation of bainitic ferrite occurs with a slow shear type mechanism. During the initial bainitic ferrite formation carbon, diffuses away in the surrounding austenite matrix. In this way favourable conditions are established for the subsequent formation of bainitic cementite also by shear. Since the obtained microstructure, on this study, are upper bainitic, this implies that carbon diffusion does not represent a kinetic obstacle for the shear transformation to occur, since as the mobile $\alpha / \gamma$ interface advances in the austenitic matrix, carbon can diffuse relatively easy. Finally an equilibrium is established at the $\alpha / \gamma$ interface that permitts the formation of cementite due to localised increased carbon concentration $[6,22]$.

\section{References}

[1] Aaronson H.I., "The mechanism of Phase transformations in Crystalline Solids", London, Institute of Metals, (1969), p.270.

[2] Lee H.J., Spanos G., Shiflet G.I. and Aaronson H.I., Acta Metall., Vol.36,(1988), 1129-1140.

[3] Ko T, and Cottrell S.A., Japan Iron Steel Inst., Vol.172, (1952), 307-315.

[4] Davenport E.S. and Bain E.C., Trans.AIME, Vol.90, (1930), 117-126.

[5] Aaronson H.I. and Kinsman K.R. , Acta Metall., Vol. 25, (1977), 367-376.

[6] Papadimitriou G., Courrier R. and Genin J.M.R., C.R.Acad. Sc.Paris, 267C, (1973), p.739.

[7] Aaronson H.I., Reynolds W.T.Jr., Shiflet G.I. and Spanos G., Met.Trans., Vol. 21A, (1990), 1343 1380.

[8] Bhadeshia H.K.D.H., Scripta Metall., Vol.21, (1987), 1605-1609.

[9] Aaronson H.I. and ReynoldsW.T. Jr., Scripta Metall., Vol.21, (1987), 1611-1614.

[10] Aaronson H.I. and Reynolds W.T. Jr., Scripta Metall., Vol.22, (1988), 567-572.

[11] Christian J.W. and Edmonds D.V., Scripta Metall., Vol. 22,(1988), 573-574.

[12] Bhadeshia H.K.D.H., Progress in Materials Science, Vol.29, (1985), 321-386.

[13] Bhadeshia H.K.D.H., "Bainite in Steels", Institute of Materials, London, (1992), pp.31-38.

[14] Oblak J.M. and Hehemann R.F., "Transformation and Hardenability in Steels", Ann Arbor MI, Climax Molybdenum Co., (1967), pp.15-39.

[15] Kaufman L. and Radcliffe S.V., "Decomposition of Austenite by Diffusional Processes", Philadelphia PA, New York Interscience, eds. (V.F. Zackay and H.I.Aaronson), (1962), pp.313-352 .

[16] Hehemann R.F., Kinsman K.R., and Aaronson H.I., Metall.Trans., Vol. 3, (1972), 1077-1094.

[17] Aaronson H.I., "Decomposition of Austenite by Diffusional Processes", Philadelphia PA, New York

NY, Interscience, eds. (Zackay V.F. and Aaronson H.I.), (1962), pp.387-547.

[18] Fourlaris G., Baker A.J. and Papadimitriou G.D., Acta Met. et Mat., Vol.43, 7 (1995), 2589-2604.

[19] Fourlaris G. and Baker A.J., Electron Microscopy, Vol.2, (1990), 204 -205.

[20] Fourlaris G., Baker A.J. and Papadimitriou G.D. , Acta Met. et Mat., Vol.43, 12 (1995), 4421-4438.

[21] Speich G.R. and Cohen M., Trans.AlME, Vol.218, (1960), 1050-1059.

[22] Papadimitriou G. and Fourlaris G., Proceedings ESOMAT ' 97

[23] Fourlaris G., Baker A.J. and Papadimitriou G.D., Acta Mat., Vol.44, 12 (1996) 4791-4805. 